\title{
Pedunculated Hepatic Hemangiomas often Misdiagnosed Despite Their Typical Findings
}

\author{
Chi D. Ha ${ }^{*}$, Scott M. Kubomoto, Brandi M. Whetstone and Salvatore Parascandola
}

Highly Artistic Plastic Surgery; 15725 Pomerado Rd Ste 212, Poway CA 92064

\begin{abstract}
Background: Hepatic hemangiomas are the most common benign liver tumors which can be often diagnosed radiologically. However despites their typical radiologic findings, giant pedunculated hemangiomas are rare and often misdiagnosed as a supra-renal, retroperitoneal, gastric, or mesenteric mass.

Methodology: The authors present a case and the summary of a thorough literature search on this rare disease entity.

Results: A 35-year-old male is found to have a $12 \mathrm{~cm}$ mesenteric mass on computed tomography and undergoes a surgical exploration. Intraoperatively, a large pedunculated hepatic hemangioma from the left lobe of the liver is encountered and removed successfully. A thorough PubMed search reveals a total of 18 publications in English with 24 cases of giant pedunculated hepatic hemangioma, most of which occur in older females, and originate from the left lobe of the liver. These tumors in general retain the typical computed tomography or magnetic resonance imaging findings of an intrahepatic hemangioma.

Conclusions: When a peri-hepatic lesion possesses typical radiologic characteristics of a hemangioma, pedunculated hemangioma should be included in the differential diagnosis.
\end{abstract}

Keywords: Pedunculated hepatic hemangioma, exophytic growth, computed tomography, magnetic resonance imaging

\section{INTRODUCTION}

Hemangioma is the most common benign hepatic tumor with autopsy prevalence between 0.4 and 20\% [1]. The majority of these lesions occur as an asymptomatic mass in the female population, and are commonly detected incidentally by abdominal ultrasonography (US), computed tomography (CT), or magnetic resonance imaging (MRI). Giant intrahepatic hemangioma can become large enough to cause symptoms due to mass effects on intrahepatic, biliary, or vascular structures as well as on the adjacent organs [2]. These lesions usually possess typical characteristics on CT or MRI, and therefore can be easily diagnosed [2, 3]. However, when the tumors develop exophytic growths outside of the liver parenchyma, they can pose difficulties in terms of radiologic diagnosis, especially when the attachment to the liver is only via a thin vascular stalk.

\section{METHODOLOGY}

We recorded the clinical presentation, treatment, and outcome of a patient with a giant pedunculated hemangioma. We then performed a thorough search on PubMed using the keywords "pedunculated," "exophytic," and "hemangioma." We also followed the resulting references to find all related article published in English.

\section{RESULTS}

A 35-year-old Sudanese man with no significant past medical or surgical history presented with a nine-month history of increasing epigastric discomfort. The patient

*Address correspondence to this author at the Highly Artistic Plastic Surgery; 15725 Pomerado Rd Ste 212, Poway CA 92064;

Tel: (858) 222-3742; Fax: (858) 206-3742; E-mail: ha_md@ surgeonsknot.com denied weight loss, fever, chills, night sweats, nausea, vomiting, rectal bleeding, bowel changes, fatigue, or malaise. Physical exam revealed a $6-\mathrm{cm}$ palpable, mobile mass just to the left of the epigastrium, which was slightly tender to palpation. The complete blood count, basic metabolic profile, and liver function studies were within normal limits. A CT scan with both oral and intravenous contrast originally reported a $12 \times 6 \times 6 \mathrm{~cm}$ heterogenous mass located within the mesentery of the transverse colon (Fig. 1).

Extensive preoperative evaluations revealed negative Echinococcus granulosus serologies, negative Entamoeba histolytica antibody titer, non-reactive Mantoux skin test, and normal levels of C-reactive protein and serum serotonin. Although an esophago-duodeno-gastroscopy showed no pathology, a colonoscopy showed extrinsic compression on the transverse colon.

Since the etiology of the mass was unknown, and since the patient continued to be symptomatic, he favored an exploratory laparotomy through a $6-\mathrm{cm}$ right subcostal incision. A large $12 \times 8 \times 4 \mathrm{~cm}$ kidney shaped multilobulated mass was discovered, attached to the edge of the left lobe of the liver by a $2 \mathrm{~cm}$ vascular pedicle which contained a $4-\mathrm{mm}$ artery and a vein. The mass was cirrhotic in texture, brownish-red in color, and appeared to be well vascularized (Fig. 2A). With the exception of a small hemangioma on the lateral aspect of the left lobe, the remainder of the liver appeared normal. The mass was removed by simply ligating the vascular pedicle. The histological analysis confirmed the diagnosis of cavernous hepatic hemangioma (Fig. 2B).

The patient had an uncomplicated postoperative course, became symptom-free, and was discharged home four days after the surgery. 


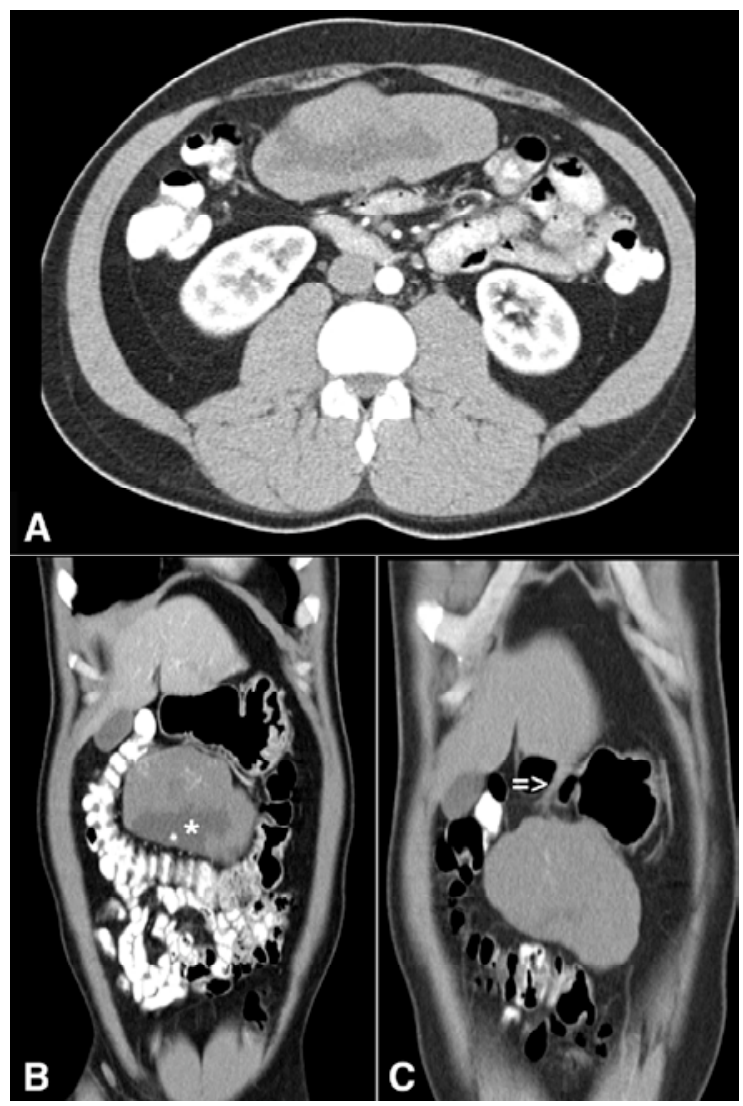

Fig. (1). Preoperative CT with intravenous and oral contrasts. (A) Arterial centripetal enhancement of the hemangioma with intravenous contrast. (B) The mass appears to be within the mesentery of the colon; however, the asterisk indicates the "bright dot" sign typical of hemangiomas. (C) A retrospective analysis reveals a small vascular pedicle (arrow).

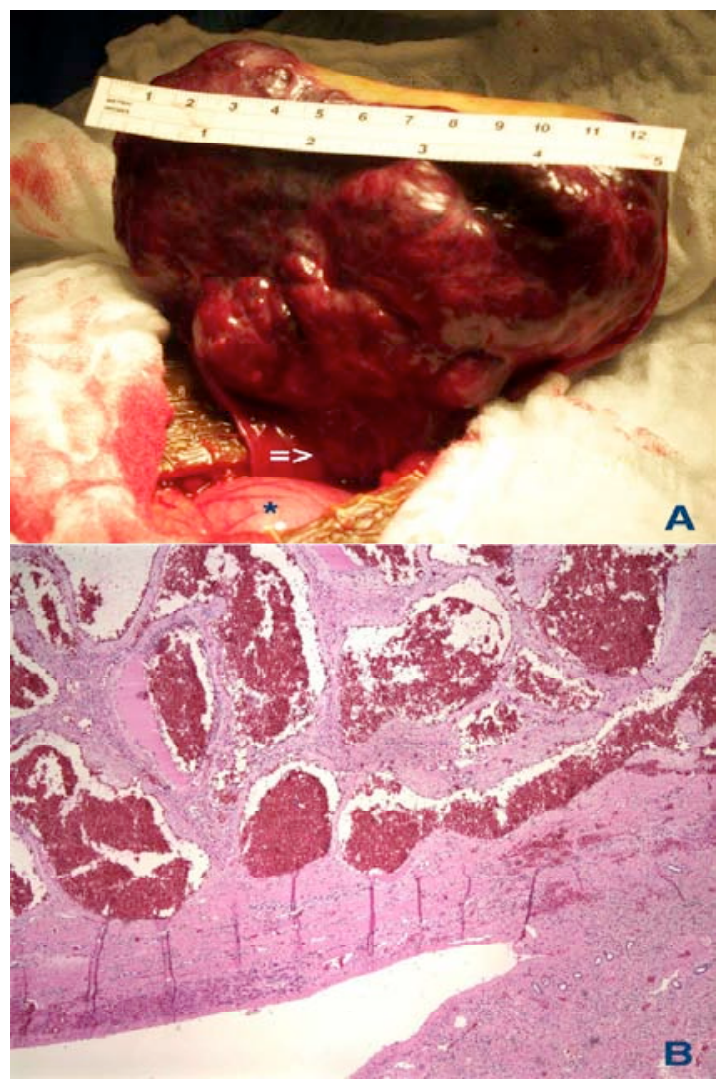

Fig. (2). (A) A large hemangiomas is suspended from the left lobe of the liver by a small vascular pedicle (arrow); asterisk indicates transverse colon. (B) Histology shows multiple thin blood-filled vessels with hyaline-like degeneration $(H \& E, x 40)$. 
Table 1. Published Data on Pedunculated Hemangioma in English Literature

\begin{tabular}{|c|c|c|c|c|c|c|c|}
\hline Authors & No. of Case & Gender & Age (Years) & Symptoms & Size $(\mathbf{c m})$ & Lobe & CT Findings \\
\hline Ellis (1985) [13] & 1 & M & 67 & none & 11 & $\mathrm{R}$ & $\mathrm{n} / \mathrm{a}$ \\
\hline Bhatnagar (1987) [14] & 1 & $\mathrm{~F}$ & 42 & duall pain & 10 & $\mathrm{~L}$ & typical* \\
\hline Luning (1988) [11] & 4 & 4 & $\mathrm{n} / \mathrm{a}$ & none & $\mathrm{n} / \mathrm{a}$ & $\mathrm{n} / \mathrm{a}$ & atypical* \\
\hline Needleman (1989) [15] & 1 & $\mathrm{~F}$ & $\mathrm{n} / \mathrm{a}$ & none & 4 & $\mathrm{R}$ & typical \\
\hline Parikh (1990) [16] & 1 & M & 71 & none & $\mathrm{n} / \mathrm{a}$ & $\mathrm{L}$ & typical \\
\hline Tran-Minh (1991) [17] & 1 & $\mathrm{~F}$ & 47 & vilvules & 8.5 & $\mathrm{~L}$ & typical \\
\hline Kumarakrishnan (1997) [18] & 1 & $\mathrm{~F}$ & 60 & none & 15 & $\mathrm{~L}$ & $\mathrm{n} / \mathrm{a}$ \\
\hline Maekawa (1997) [19] & 1 & M & 62 & none & 4 & $\mathrm{R}$ & $\mathrm{n} / \mathrm{a}$ \\
\hline Srivastava (1998) [20] & 1 & $\mathrm{~F}$ & 53 & none & 15 & $\mathrm{R}$ & typical \\
\hline Nishiyama (1999) [21] & 1 & $\mathrm{~F}$ & 55 & pain & 5 & $\mathrm{~L}$ & typical \\
\hline Tsai (1999) [22] & 1 & $\mathrm{~F}$ & 53 & none & 15 & $\mathrm{~L}$ & typical \\
\hline Cortés-Blanco (2000) [23] & 1 & $\mathrm{~F}$ & 60 & jaundice & 15 & $\mathrm{~L}$ & $\mathrm{n} / \mathrm{a}$ \\
\hline Vilgrain (2000) [24] & 1 & $\mathrm{n} / \mathrm{a}$ & $\mathrm{n} / \mathrm{a}$ & $\mathrm{n} / \mathrm{a}$ & 6 & $\mathrm{~L}$ & $\mathrm{n} / \mathrm{a}$ \\
\hline \multirow[t]{2}{*}{ Bader (2001) [12] } & 1 & $\mathrm{n} / \mathrm{a}$ & $\mathrm{n} / \mathrm{a}$ & pain & 5 & $\mathrm{~L}$ & $\mathrm{n} / \mathrm{a}$ \\
\hline & 1 & $\mathrm{n} / \mathrm{a}$ & $\mathrm{n} / \mathrm{a}$ & pain & 3.5 & $\mathrm{~L}$ & $\mathrm{n} / \mathrm{a}$ \\
\hline Brancatelli (2001) [25] & 2 & $\mathrm{n} / \mathrm{a}$ & $\mathrm{n} / \mathrm{a}$ & $\mathrm{n} / \mathrm{a}$ & $\mathrm{n} / \mathrm{a}$ & $\mathrm{n} / \mathrm{a}$ & typical \\
\hline \multirow[t]{2}{*}{ Liang (2002) [26] } & 1 & $\mathrm{~F}$ & 42 & none & 5 & $\mathrm{~L}$ & Typical \\
\hline & 1 & M & 36 & none & 5 & $\mathrm{~L}$ & typical \\
\hline Hosokawa (2005) [27] & 1 & $\mathrm{~F}$ & 69 & none & 6 & $\mathrm{R}$ & atypical \\
\hline Masui (2005) [28] & 1 & $\mathrm{~F}$ & 49 & none & 10 & $\mathrm{~L}$ & typical \\
\hline \multirow[t]{2}{*}{$\mathrm{Ha} \mathrm{(2008)}$} & 1 & M & 35 & pain & 12 & $\mathrm{~L}$ & typical \\
\hline & 25 & $\mathrm{M}: \mathrm{F}=5: 11$ & $53(35-71)$ & Sx:Asx $=8: 10$ & $8.6(3.5-15)$ & $\mathrm{R}: \mathrm{L}=5: 14$ & $85 \%$ typical \\
\hline
\end{tabular}

n/a: information not available; F: female; M: male; Sx: symptomatic; Asx: symptomatic; CT: computed tomography; R: right; L: left

(*) typical and atypical CT findings of hemangioma as described in text

\section{DISCUSSION}

Cavernous hemangiomas were considered vascular malformations or hamartomas of congenital origin that arised by ectasia [4]. These tumors could measure from several millimeters up to $20 \mathrm{~cm}$ in size, and were considered "giant" if the lesion was greater than $4 \mathrm{~cm}$ in diameter [5]. They had a female predominance (3:1), and were usually discovered between the ages of 30 and 50 years. ${ }^{6}$ Most cavernous hemangiomas were asymptomatic, were less than $5 \mathrm{~cm}$ in size, located within the parenchyma of the right hepatic lobe, and were incidentally found on imaging for other reasons [4]. Larger hemangiomas (those larger than $5 \mathrm{~cm}$ ) were more likely to present with symptoms of mass effect such as intermittent abdominal pain, right upper quadrant discomfort or fullness, early satiety, nausea, and anorexia [5]. Thrombosis or hemorrhage, and the resulting distention of Glisson capsule, could lead to acute severe abdominal pain, elevated liver function enzymes, and fevers [7].

Most hemangiomas followed a benign course, and often did not enlarge or increase patient morbidity [6]. For asymptomatic patients or those with hemangiomas measuring less than $5 \mathrm{~cm}$, observation alone was appropriate [4]. For symptomatic patients and/or hemangiomas larger than $5 \mathrm{~cm}$, several approaches had been studied. Non-surgical options included hepatic arterial embolization, [8] radiation [9], or interferon alpha-2a [10]. Enucleation was currently the preferred surgical treatment, followed by liver resection [4].
Hepatic hemangiomas were considered pedunculated or exophytic if the tumor clearly extended beyond the border of the liver [11] or if the center of the lesion was located outside of the expected margins of the liver [12]. To our knowledge, giant pedunculated hemangiomas were very rare. The first reported case of giant pedunculated hepatic hemangioma was by Ellis et al. in 1985 [13]. Our thorough PubMed search of the published English literature on pedunculated hemangioma using the keywords "hepatic," "hemangioma," "pedunculated," and "exophytic" yielded only 18 articles, with 24 total cases cited (Table 1) [11-28]. We included in Table $\mathbf{1}$ our current case in an attempt to derive meaningful statistics.

Based on the data available on these cases, we were able to gain important information. Pedunculated hemangiomas appeared to have female predominance $(69 \%)$, which might reflect an association with estrogen exposure [29]. Close to half of the patients (44\%) developed symptoms at the time of presentation. This might be due to the large mean tumor size of $8.6 \mathrm{~cm}$. This finding was consistent with the similar findings that intrahepatic hemangioma was usually symptomatic if the size is greater than $5 \mathrm{~cm}$ [6]. The majority of pedunculated tumors (74\%) occured in the left lobe of the liver. A possible explanation for this was that the left lobe had a greater surface area to volume ratio versus the right lobe, and therefore the protrusion of a parenchymal mass was more likely. Patient age ranged from 35-71 years with a 
mean age of 53. This fact might support the notion that hepatic hemangioma, resumed to be congenital in origin, was a slowly-developing tumor [6]. The most important observation derived from this pool of data was the fact that despite the exophytic growth, $85 \%$ of these tumors maintained the typical radiographic findings of an intrahepatic hemangioma.

Our CT scan protocol and most of those used in the cases of pedunculated hemangioma were similar to that described by Brancatelli [25]. A 64-slice scanner was used with $150 \mathrm{~mL}$ of $60 \%$ iodinated contrast medium at the rate of $5 \mathrm{~mL}$ per second. The hepatic arterial phase was scanned at 25 seconds, and the portal venous-dominant phase was scanned at 60 seconds after the administration of the contrast. An additional delay phase was performed at 14 minutes.

On a non-contrast CT scan, a cavernous hemangioma typically appeared to be hypodense compared to normal liver parenchyma. However, during the arterial phase of a CT scan with contrast, an early nodular peripheral enhancement with a gradual filling-in of opacity from the periphery towards the center of the lesion could be observed [11, 25]. Strictly speaking, for an intrahepatic hemangioma the completion of this filling-in effect should occur within 3 and 60 minutes after the contrast administration [30]. Occasionally, the center of the lesion might not be filled with opacity. This might be due to a large cystic, necrotic, or scarred area within the middle of the lesion [31]. In addition, Jang et al. described a tiny enhancing dot ("bright dot" sign) in the hepatic arterial phase and portal venous phase of two-phase spiral CT as characteristic of small $(<2 \mathrm{~cm})$ hemangiomas [32].

In our case, the tumor demonstrated the CT findings typical of hemangiomas, including arterial phase centripetal enhancement (Fig. 1A). In addition, a "bright dot" sign was found within the lesion (Fig. 1B).

MRI could also be used to identify hepatic hemangioma. Interestingly, pedunculated hemangiomas also retained the MRI characteristics typical of those of the intrahepatic lesions. These lesions typically appeared as a well demarcated homogenous mass with moderately low signal T1-weighted images, and high signal on T2-weighted images [12]. On hepatic arterial dominant phase post gadolinium images they showed nodular peripheral enhancement with inward progression of enhancement on delayed image [12].

Although the hemangioma in our case possessed typical characteristics of a hemangioma, its vascular pedicle was not readily visualized. Therefore, our initial extensive workup was focused on a mesenteric mass of uncertain etiology. A retrospective analysis of the original CT-scan showed a subtle attachment to the left lobe of the liver (Fig. 1C).

The inability to visualize the vascular pedicle was probably the main reason for misdiagnosis of a pedunculated hepatic hemangioma, even though it demonstrated typical radiographic findings. There had been several cases in the literature where this occurs. Ellis et al described a hemangioma that was confused with a large right suprarenal mass on CT. The pedunculated hemangioma was later found to be compressing the right adrenal gland [13]. Needleman et al described a case in which a pedunculated hemangioma was mistaken for a retroperitoneal mass because the retroperitoneal fat appeared to be anterior to the hemangioma
[14]. Likewise, Nishiyama et al found a pedunculated hemangioma that radiographically imitated a submucosal gastric tumor [21]. All of these lesions, including ours, were in the vicinity of the liver and possess the radiographic characteristics of a hemangioma. Therefore, hemangioma should be included in the initial differential diagnosis.

\section{CONCLUSION}

Our report discusses the confusion caused by the unusual location of an otherwise radiographically typical cavernous hemangioma. While pedunculated cavernous hemangiomas are rare, considering them in the differential diagnosis of an extrahepatic mass that has the radiographic features of a cavernous hemangioma can limit unnecessary work-ups and potentially harmful procedures such as needle biopsy which would pose a significant bleeding risk. One could also prevent unnecessary surgical intervention for incidentallyfound, asymptomatic hemangiomas.

\section{ABBREVIATION}

$$
\begin{aligned}
& \mathrm{US}=\text { ultrasonography) } \\
& \mathrm{CT}=\text { computed tomography) } \\
& \mathrm{MRI}=\text { magnetic resonance imaging }
\end{aligned}
$$

\section{CONFLICT OF INTEREST}

The authors confirm that this article content has no conflicts of interest.

\section{ACKNOWLEDGEMENT}

Declared none.

\section{REFERENCES}

[1] Powers C, Ros PR, Stoupis C, et al. Primary liver neoplasms: MR imaging with pathologic correlation. Radiographics 1994; 14: 47982.

[2] Danet IM, Semelka RC, Braga L, et al. Giant hemangioma of the liver: MR imaging characteristics in 24 patients. Magn Reson Imaging 2003; 21: 95-101.

[3] Choi BI, Han MC, Park JH, et al. Giant cavernous hemangioma of the liver: CT and MR imaging in 10 cases. AJR 1989; 152: 1221-6.

[4] Karnam US, Reddy KR. Chapter 47-Approach to the patient with a liver mass. In: Yamada et al, Eds. Textbook of Gasteroenterology, $4^{\text {th }}$ ed. Philadelphia: Lippincott Williams \& Walkins 2003: pp. 973-4.

[5] Adam YG, Huvos AG, Fortner JG. Giant hemangiomas of the liver. Ann Surg 1970; 172: 239-45.

[6] Gandolfi L, Leo P, Solmi L, et al. Natural history of hepatic haemangiomas: clinical and ultrasound study. Gut 1991; 32: 67780.

[7] Pateron D, Babany G, Belghiti J, et al. Giant hemangioma of the liver with pain, fever, and abnormal liver tests. Report of two cases. Dig Dis Sci 1991; 36: 524-7.

[8] Giavroglou C, Economou H, Ioannidis I. Arterial embolization of giant hepatic hemangiomas. Cardiovasc Intervent Radiol 2003; 26: 92-6.

[9] Gaspar L, Mascarenhas F, da Costa MS, et al. Radiation therapy in the unresectable cavernous hemangioma of the liver. Radiother Oncol 1993; 29: 45-50.

[10] Schiavetti A, De Pasquale MD, Di Salvo S, et al. Recombinant interferon alfa $2 \mathrm{a}$ in hepatic hemangiomatosis with congestive heart failure: a case report. Pediatr Hematol Oncol 2003; 20: 161-5.

[11] Luning M, Muhler A. CT Diagnosis of pedunculated liver tumours. Eur J Radiol 1988; 8: 221-5.

[12] Bader TR, Braga L, Semelka RC. Exophytic benign tumors of the liver: appearance on MRI. Magn Reson Imaging 2001; 19: 623-8.

[13] Ellis JV, Salazar JE, Gavant ML. Pedunculated hepatic hemangioma: An unusual cause for anteriorly displaced retroperitoneal fat. J Ultrasound Med 1985; 4: 623-4. 
[14] Bhatnagar A, Pathania OP, Champakam NS. Giant pedunculated haemangioma of the liver. Indian J Gastroenterol 1987; 6(1): 51-2.

[15] Needleman L, Wechsler RJ, Kurtz AB. Ultrasound case of the day. Pedunculated retroperitoneal liver hemangioma. Radiographics 1989; 9: 769-73.

[16] Parikh VP, Iyer GN. Pedunculated hepatic hemangioma: CT findings. AJR 1990; 155: 1137-8.

[17] Tran-Minh VA, Gindre T, Pracros JP, et al. Volvulus of a pedunculated hemangioma of the liver. AJR 1991; 156: 866-7.

[18] Kumarakrishnan S, Gupta A, Srinivasan K, et al. Pedunculated giant hemangioma of liver. Indian J Gastroenterol 1997; 16: 35-6.

[19] Maèkawa S, Mizutani Y, Terachi T, et al. A case of exophytic hepatic hemangioma mimicking adrenal tumor. Hinyokika Kiyo 1997; 43(2): 123-6.

[20] Srivastava DN, Sharma S, Yadav S, et al. Pedunculated hepatic haemangioma with arterioportal shunt: treated with angioembolization and surgery. Aust Radiol 1998; 42(2): 151-3.

[21] Nishiyama Y, Yamamoto Y, Fukunaga K, et al. Pedunculated hepatic hemangioma identified on Tc-99m DTPA-HSA scintigraphy. Clin Nucl Med 1999; 24(2): 133-4.

[22] Tsai CC, Yen TC, Tzen KY. Pedunculated giant liver hemangioma mimicking a hypervascular gastric tumor on Tc-99m RBC SPECT. Clin Nucl Med 1999; 24(2): 132-3.

[23] Cortés-Blanco A, Martínez-Lázaro R. Bile duct stenosis seemingly caused by a giant pedunculated hemangioma with hypogastric growth. Clin Nucl Med 2000; 25(4): 299-300.
[24] Vilgrain V, Boulos L, Vullierme MP, et al. Imaging of atypical hemangiomas of the liver with pathologic correlation. Radiographics 2000; 20(2): 379-97.

[25] Brancatelli G, Federle MP, Blachar A, et al. Hemangioma in the cirrhotic liver: diagnosis and natural history. Radiology 2001; 219(1): 69-74.

[26] Liang RJ, Chen $\mathrm{CH}$, Chang YC, et al. Pedunculated hepatic hemangioma: report of two cases. J Formos Med Assoc 2002; 101(6): 437-41.

[27] Hosokawa A, Maeda T, Tateishi U, et al. Hepatic hemangioma presenting atypical radiologic findings: a case report. Radiat Med 2005; 23(5): 371-5.

[28] Masui T, Katayama M, Nakagawara M, et al. Exophytic giant cavernous hemangioma of the liver with growing tendency. Radiat Med 2005; 23(2): 121-4

[29] Glinkova V, Shevah O, Boaz M, et al. Hepatic haemangiomas: possible association with female sex hormones. Gut 2004; 53: $1352-5$.

[30] Nelson RC, Chezmar JL. Diagnostic approach to hepatic hemangiomas. Radiol 1990; 176: 11-3.

[31] Yamashita Y, Ogata I, Urata J, et al. Cavernous hemangioma of the liver: pathologic correlation with dynamic CT findings. Radiol 1997; 203: 121-5.

[32] Jang HJ, Choi BI, Kim TK, et al. Atypical small hemangiomas of the liver: "bright dot" sign at two-phase spiral CT. Radiol 1998; 208(2): 543-8

(C) Ha et al.; Licensee Bentham Open.

This is an open access article licensed under the terms of the Creative Commons Attribution Non-Commercial License (http://creativecommons.org/licenses/by$\mathrm{nc} / 3.0 /$ ), which permits unrestricted, non-commercial use, distribution and reproduction in any medium, provided the work is properly cited. 